\title{
Endoscopic evaluation of patients with gastric wall thickening detected with computed tomography
}

\author{
๑ Bilge Baş, $\odot$ Zehra Betul Pakoz, ${ }^{2} \odot$ Erkan Oymacl $^{3}$ \\ 'Department of Gastroenterology, Antalya Training and Research Hospital, Antalya, Turkey \\ 2Department of Gastroenterology, Tepecik Training and Research Hospital, İzmir, Turkey \\ ${ }^{3}$ Department of Gastroenterologic Surgery, Bozyaka Training and Research Hospital, İzmir, Turkey
}

\begin{abstract}
Introduction: The objective of this study was to evaluate the endoscopy results of patients with gastric wall thickening detected in the upper gastrointestinal tract based on computed tomography imaging performed to investigate different complaints.
\end{abstract}

Materials and Methods: The results of patients who were referred between October 2009 and March 2015 after computed tomography imaging demonstrated upper gastrointestinal system wall thickening and who underwent endoscopy were reviewed retrospectively. Patient data of age, gender, the location of the thickening detected with radiological imaging, hemoglobin values, endoscopy findings, and diagnosis were analyzed.

Results: A total 171 patients underwent gastroscopy for upper gastrointestinal wall thickening. Forty-three (25.1\%) of the patients were diagnosed with stomach cancer, $87(50.8 \%)$ with gastritis, $8(4.6 \%)$ had a hiatal hernia, $7(40.09 \%)$ had a gastric polyp, and $20(11.6 \%)$ had a gastric ulcer. Six patients $(3.5 \%)$ had normal results. Patients with gastritis had a mean hemoglobin level of $12.6 \mathrm{~g} / \mathrm{dL}$ compared with $10.09 \mathrm{~g} / \mathrm{dL}$ in those with stomach cancer $(p<0.001)$. Patients with an ulcer had a mean hemoglobin level of $10.8 \mathrm{~g} / \mathrm{dL}$ compared with $12.6 \mathrm{~g} / \mathrm{dL}$ in patients with gastritis $(\mathrm{p}<0.001)$. Among the patients with wall thickening in the upper gastrointestinal system and malignancy, $83.7 \%$ were over 50 years of age and $51 \%$ had a hemoglobin level below $10 \mathrm{~g} / \mathrm{dL}$.

Conclusion: Wall thickening detected in the gastrointestinal system with radiological imaging may be a sign of malignancy, especially in patients who are over 50 years of age and have a hemoglobin level below $10 \mathrm{~g} / \mathrm{dL}$.

Keywords: Computed tomography; stomach; wall thickness.

\section{Introduction}

Increased wall thickness in the gastrointestinal system (GIS) is an important finding. Increased wall thickness due to a variety of causes including benignant and malignant lesions, inflammation and post-operative changes can be seen with computed tomography (CT). While en- doscopy is the golden standard in upper gastrointestinal assessments, CT also provides critical information. ${ }^{[1,2]}$ GIS wall thickenings are also frequently noted as a result of imaging procedures taken due to non-GIS complaints. ${ }^{[3]}$ Further investigation with endoscopy is recommended since it cannot be understood whether this finding is un-

Received: 12.01.2019 Accepted: 14.03.2019

Correspondence: Zehra Betül Paköz, M.D., Department of Gastroenterology, Tepecik Training

and Research Hospital, İzmir, Turkey, Turkey

e-mail: betulpakoz@yahoo.com 
derlain by a malignant or benignant condition or is totally a normal finding. ${ }^{[4]}$ While $5 \mathrm{~mm}$ is acknowledged as the threshold for wall thickness at the corpus and antrum, it may often not indicate a more serious condition because gastritis due to Helicobacter pylori infection common in the antrum is seen frequently. ${ }^{[5,6]}$

Increased wall thickness secondary to edema may also be seen when the patient has another condition such as cirrhosis, heart failure, nephrotic syndrome and hypoalbuminemia. ${ }^{[7]}$

There is still no algorithm for approaches to be followed for patients presenting with findings of GIS wall thickening.

The objective of this study is to evaluate our endoscopy results in subjects with gastric wall thickening detected in the upper gastrointestinal tract with computed tomography imaging performed to investigate different complaints.

\section{Materials and Methods}

The results of patients for whom GIS wall thickening was identified with CT taken for varying indications in different healthcare centers between October 2009 and March 2015 and who were referred to the gastroenterology clinic and underwent gastroscopy to investigate GIS wall thickening were reviewed retrospectively. Values above $5 \mathrm{~mm}$ were considered as increased wall thickness for the stomach. The demographic data, hemoglobin values and endoscopy results of the patients included in the study were analyzed. Excluding patients with known prior GIS pathology (malignancy, inflammatory bowel disease, hiatal hernia) and those with conditions that may result in GIS thickenings such as heart failure, cirrhosis, nephrotic syndrome and hypoalbuminemia, all patients over 18 years of age with no past GIS surgery were included in the study.

Statistical analyses were performed using the SPSS 21.0 software for this study. Patients' demographical and clinical characteristics were expressed as mean \pm standard deviation (SD), median and percentage. Parametric data were evaluated using Student's t-test and non-parametric data with Mann-Whitney $U$ and $\chi^{2}$ tests. Statistical significance was set at $\mathrm{p}<0.05$.

\section{Results}

Gastroscopy was performed for a total of 171 patients because upper GIS wall thickening was detected with tomography.
Forty-three (25.1\%) of the patients had stomach cancer, 87 (50.8\%) had gastritis, 8 (4.6\%) had a hiatal hernia, 7 (4.09\%) had a gastric polyp, and 20 (11.6\%) had a gastric ulcer. Six (3.5\%) patients had normal results (Table 1).

Ninety-eight of them were men and 73 were women, and their mean age was 57 (28-80) years. While mean age of the patients with gastric cancer was 64.5 years, mean age in patients with gastritis was 53.2 years $(\mathrm{p}<0.05)$.

Overall, the patients had a mean hemoglobin level of 11.4 $\mathrm{g} / \mathrm{dL}$. Mean hemoglobin level in patients with benign conditions was $11.65 \mathrm{~g} / \mathrm{dL}$, compared with $10.09 \mathrm{~g} / \mathrm{dL}$ in patients with stomach cancer $(\mathrm{p}<0.001)$. Similarly, there was a significant difference in hemoglobin levels between polyp and gastritis $(11.1 \mathrm{~g} / \mathrm{dL}$ and $12.6 \mathrm{~g} / \mathrm{dL}$, respectively. $\mathrm{p}<0.001)$. Significant different hemoglobin levels found between the patients with gastritis and gastric carcinoma $(\mathrm{p}<0.001)$. Comparison of mean hemoglobin levels between malign and benign conditions summarized in Table 2.

Table 1. Endoscopy results of patients with gastric wall thickness detected with tomography

\begin{tabular}{lcc} 
Conditions & \multicolumn{2}{c}{ Number of patients } \\
\cline { 2 - 3 } & $\mathbf{n}$ & $\%$ \\
\hline Normal & 6 & 3.5 \\
Malignancy & 43 & 23.1 \\
Gastritis & 87 & 50.8 \\
Hiatal hernia & 8 & 4.6 \\
Polyp & 7 & 4.09 \\
Ulcer & 20 & 11.6 \\
\hline
\end{tabular}

Table 2. Comparison of mean hemoglobin levels of the patients

\begin{tabular}{lcc} 
Conditions & Hemoglobin levels & p \\
\hline Overall & $11.4 \mathrm{~g} / \mathrm{dL}$ & \\
Benign conditions & $11.65 \mathrm{~g} / \mathrm{dL}$ & \\
Malignancy & $10.09 \mathrm{~g} / \mathrm{dL}$ & $<0.001 *$ \\
Gastritis & $12.6 \mathrm{~g} / \mathrm{dL}$ & $<0.001^{* *}$ \\
Hiatal hernia & $12.1 \mathrm{~g} / \mathrm{dL}$ & $>0.05^{+}$ \\
Polyp & $11.1 \mathrm{~g} / \mathrm{dL}$ & $<0.001^{\dagger}$ \\
Ulcer & $10.8 \mathrm{~g} / \mathrm{dL}$ & $<0.001^{+}$
\end{tabular}

*Compared to benign conditions; **Compared to malignancy; ${ }^{\dagger}$ Compared to gastritis. 
Of the patients with upper GIS wall thickness with detected malignancies, $83.7 \%$ were over 50 years of age and $51 \%$ had hemoglobin levels below $10 \mathrm{~g} / \mathrm{dL}$.

\section{Discussion}

High-quality upper GIS assessment can be made, especially with thin-section CT imaging. Increased wall thickness can be detected with CT due to several reasons including malignancies, benignant lesions, inflammation, varices and post-operative changes. ${ }^{[8]}$

A study by Tongdee et al. ${ }^{[9]}$ in 2004 found malignancies in 22 of 154 (14.2\%) patients who underwent endoscopy after their tomography showed wall thickness. Benignant conditions were found in 66 of these patients (42.8\%) and had normal endoscopy findings.

Another study in 2003 included 36 patients with gastric wall thickness detected with tomography. Patients' endoscopy demonstrated two concurrent lesions in two patients, resulting in a total of 38 lesions. 19 (50\%) of the lesions were gastritis, 4 (10.5\%) were a hiatal hernia, 3 (7.9\%) were an ulcer, 3 (7.9\%) were benignant neoplasms and $11(28.9 \%)$ were malignant neoplasms. One $(2.6 \%)$ of the patients had normal upper GIS endoscopy. ${ }^{[10]}$ In this study, the increased wall thickness of $10 \mathrm{~mm}$ and above had a 100\% sensitivity and 50\% specificity.

A study by Cereceda Pérez et al. ${ }^{[1]]}$ in 2002 evaluated the differentiation of malignant and benignant conditions of the stomach. Ninety-two patients with clinically suspected pathologies underwent CT and endoscopy. Wall thickening above $6 \mathrm{~mm}$ with CT was considered as increased wall thickness. Twelve (13\%) patients had normal findings with CT and endoscopy. Of the 80 pathological cases in total, 29 (31.5\%) yielded benignant and 51 (55.4\%) malignant findings. Malignancy rate was lower in our study and in other studies. This may be because of the fact that CT was taken due to suspected gastric pathology in the study by Cereceda Pérez et al. wall thickening was incidentally detected in our study and other studies.

Although H. pylori-associated gastritis is known to increase antral wall thickness to above $5 \mathrm{~mm}$, a study by Kul et al. ${ }^{[6]}$ in 2008 observed no significant increase in wall thickness among $\mathrm{H}$. pylori-positive patients compared with negative patients. A study by Urban et al. ${ }^{[12]}$ reported no significant gastric wall thickening in $\mathrm{H}$. Pylori infection.

Tellez-Avila et al. ${ }^{[13]}$ found gastric cancer in 6 of 21 patients with wall thickening detected with CT. The authors re- ported that patient age or gender was not a valid criterion when a decision for endoscopy was to be made. Powell et al. ${ }^{[14]}$ reported that a gastroenterological evaluation should be performed especially in patients with iron deficiency anemia who are over 70 years of age. A study by Park et al., ${ }^{[15]}$ found significantly more GIS malignancies in patients with iron deficiency and anemia compared with those without anemia. A study in Taiwan observed significantly more gastroenterological malignancies in patients who are 60 years of age and have hemoglobin levels below $8.8 \mathrm{~g} / \mathrm{dL} .{ }^{[16]}$

The rates of detecting GIS wall thickening with imaging methods and finding pathologies as a result of endoscopic investigations differ considerably among healthcare facilities. This may be due to factors such as the quality of the radiographic procedure, use of contrast agent and experience of the physician evaluating the investigation.

GIS wall thickenings found incidentally in tomography images performed for various reasons are clinically important. The likelihood of finding a pathology increases especially if the patient is elderly and has low hemoglobin values.

\section{Conclusion}

Benignant or malignant lesions in the stomach may cause wall thickening in tomography. Detecting gastrointestinal system wall thickening with tomography may indicate a malignancy especially in patients who are over 50 years of age and have hemoglobin values less than $10 \mathrm{~g} / \mathrm{dL}$. We believe that more careful evaluating of these patients with endoscopic methods may be benefit in terms of early diagnosis.

\section{Disclosures}

Ethichs Committee Approval: The study was approved by the Local Ethics Committee.

Peer-review: Externally peer-reviewed.

Conflict of Interest: None declared.

\section{References}

1. Fishman EK, Urban BA, Hruban RH. CT of the stomach: spectrum of disease. Radiographics 1996;16:1035-54.

2. Kim JY, Kim SH, Lee JM, Han JK, Lee JY, Choi BI. Differentiating malignant from benign wall thickening in postoperative stomach using helical computed tomography: results of multivariate analysis. J Comput Assist Tomogr 2007;31:455-62. 
3. Ergul B, Filik L. Clinical approach to gastrointestinal wall thickening: a prospective single center study. Endoscopy 2012;20:29-31.

4. Al-Khowaiter SS, Brahmania M, Kim E, Madden M, Harris A, Yoshida EM, et al. Clinical and endoscopic significance of bowel-wall thickening reported on abdominal computed tomographies in symptomatic patients with no history of gastrointestinal disease. Can Assoc Radiol J 2014;65:67-70.

5. Pickhardt PJ, Asher DB. Wall thickening of the gastric antrum as a normal finding: multidetector CT with cadaveric comparison. AJR Am J Roentgenol 2003;181:973-9.

6. Kul S, Sert B, Sari A, Arslan M, Koşucu P, Ahmetoğlu A, et al. Effect of subclinical Helicobacter pylori infection on gastric wall thickness: multislice CT evaluation. Diagn Interv Radiol 2008;14:138-42.

7. Karim MS, Miranda MC, Shamma'a JM, Goebel SU, Sundaram U. Utility of upper endoscopy and colonoscopy in evaluating gastrointestinal luminal wall thickening found on computed tomography. W V Med J 2010;106:16-9.

8. Ba-Ssalamah A, Prokop M, Uffmann M, Pokieser P, Teleky B, Lechner $\mathrm{G}$. Dedicated multidetector $\mathrm{CT}$ of the stomach: spectrum of diseases. Radiographics 2003;23:625-44.

9. Tongdee R, Kongkaw L, Tongdee T. A study of wall thickness of gastric antrum: comparison among normal, benign and malignant gastric conditions on MDCT scan. J Med Assoc Thai 2012;95:1441-8.

10. Insko EK, Levine MS, Birnbaum BA, Jacobs JE. Benign and malignant lesions of the stomach: evaluation of CT criteria for differentiation. Radiology 2003;228:166-71.

11. Cereceda Pérez CN, Urbasos Pascual MI, Romero Castellanos C, Carreira Gómez C, Pinto Varela JM. Helical CT of the stomach: differentiation between benign and malignant pathologies, together with the staging of gastric carcinoma. Rev Esp Enferm Dig 2002;94:601-12. [Article in English, Spanish]

12. Urban BA, Fishman EK, Hruban RH. Helicobacter pylori gastritis mimicking gastric carcinoma at CT evaluation. Radiology 1991;179:689-91.

13. Tellez-Avila FI, García-Osogobio S, Chavez-Tapia NC, Ramirez-Luna MA, Franco-Guzman A, Sosa-Lozano A, et al. Utility of endoscopy in patients with incidental gastrointestinal luminal wall thickening detected with CT. Surg Endosc 2009;23:2191-6.

14. Powell N, McNair A. Gastrointestinal evaluation of anaemic patients without evidence of iron deficiency. Eur J Gastroenterol Hepatol 2008;20:1094-100.

15. Park JS, Park DI, Park SK, Choi JS, Kim YH, Chang DK, et al. Endoscopic evaluation of significant gastrointestinal lesions in patients with iron deficiency with and without anaemia: a Korean Association for the Study of Intestinal Disease study. Intern Med J 2009;39:441-6.

16. Ho CH, Chau WK, Hsu HC, Gau JP, You JY, Chen CC. Predictive risk factors and prevalence of malignancy in patients with iron deficiency anemia in Taiwan. Am J Hematol 2005;78:108-12. 